\title{
PANORAMA NACIONAL DAS CONDIÇÕES DE GESTÃO NO ENSINO FUNDAMENTAL
}

\author{
PANORAMA NACIONAL DE LAS CONDICIONES DE GESTIÓN EN LA \\ EDUCACIÓN FUNDAMENTAL
}

\author{
NATIONAL PANORAMA OF ADMINISTRATION'S CONDITIONS AT \\ ELEMENTARY SCHOOL
}

Ângelo Ricardo de SOUZA ${ }^{1}$

Marcus Quintanilha da SILVA ${ }^{2}$

RESUMO: O presente trabalho tem por objetivos descrever a metodologia de construção e analisar os resultados do Índice de Condições de Gestão (ICG), um dos três indicadores parciais do Índice de Condições de Qualidade (ICQ) da Educação, fomentado pelas informações dos questionários de contexto dos $5^{\circ} \mathrm{s}$ anos da Prova Brasil. Evidenciou-se alta desigualdade interestadual, caracterizando um cenário de distância da efetividade dos instrumentos de gestão democrática analisados pelo ICG: forma de provimento do diretor/a, existência e efetividade dos Conselhos de Escola e a forma de construção do Projeto Político Pedagógico, assim como alta variação no conjunto das redes municipais dentro de cada estado.

PALAVRAS-CHAVE: Condições de gestão educacional. Ensino fundamental. Gestão democrática. Políticas educacionais.

RESUMEN: El presente trabajo tiene por objetivos describir la metodología de construcción y analizar los resultados del Índice de Condiciones de Gestión (ICG), uno de los tres indicadores parciales del Índice de Condiciones de Calidad (ICQ) en la educación, fomentado por las informaciones de los cuestionarios de contexto de los $5^{\circ}$ años de la Prueba Brasil. Se evidenció una alta desigualdad interestatal, caracterizando un escenario de distancia de la efectividad de los instrumentos de gestión democrática analizados por el ICG: forma de provisión del director/a, existencia y efectividad de los Consejos de Escuela y la forma de construcción del Proyecto Político Pedagógico, así como de alta variación en el conjunto de las redes municipales dentro de cada estado.

PALABRAS CLAVE: Condiciones de gestión educativa. Educación fundamental. Gestión democrática. Políticas educativas.

1 Universidade Federal do Paraná (UFPR), Curitiba - PR. Professor Associado do Núcleo de Políticas Educacionais (NuPE) e do Programa de Pós-Graduação em Educação (PPGE). ORCID: <https://orcid.org/00000002-0246-3207>.E-mail: angelo@ufpr.br

${ }^{2}$ Universidade Federal do Paraná (UFPR) e Secretaria Municipal de Educação de Curitiba (SME), Curitiba-PR. Mestre e Doutorando em Educação (UFPR). ORCID: <https://orcid.org/0000-0002-8305-0024>. E-mail: marcusquintanlha@ hotmail.com. 
ABSTRACT: The objective of this study is to describe the methodology of construction and analyze the results of the Administration Conditions Index (ICG), one of the three indicators of the Education Quality Index (ICQ), fostered by information from the context questionnaires of Brazilian National Evaluation. High interstate inequality was evidenced, characterizing a scenario away from the effectiveness of the democratic administration instruments analyzed by the ICG: strategies of director's provision, existence and effectiveness of School Boards and the form of Political Pedagogical Project construction, as well as in all municipal education systems within each state.

KEYWORDS: Educational administration conditions. Elementary school. Democratic administration. Educational policies.

\section{Introdução}

Há muitas formas de se enfrentar o debate da qualidade na educação, desde a análise do processo de organização do trabalho escolar, passando pelo estudo das condições de trabalho, da gestão da escola, do currículo, da formação dos docentes, da análise das condições materiais da escola, até a análise de sistemas e instituições de ensino expressas por avaliações externas (DOURADO; OLIVEIRA; SANTOS, 2007).

Baseando-se em uma educação de qualidade, os autores supracitados enfatizam que os custos para tal apresentam aspectos gerais a serem considerados, evidenciando alguns elementos para se pensar em uma escola com qualidades fundamentais (ou condições de qualidade), indicando importantes condicionantes para as condições de oferta.

No intuito de trabalhar a qualidade da educação no ponto de vista das condições de oferta, entende-se que, em um cenário ideal para um processo que culmine em uma oferta de ensino de qualidade, o caminho deve reunir condições não mínimas de financiamento, condições de qualidade no processo e consolidação da aprendizagem. Ou seja, a proposta de Dourado, Oliveira e Santos (2007) sobre a tríade insumos-processos-resultados como um percurso ideal da efetividade da política educacional com qualidade é entendida como fundamental, ainda que este trabalho se concentre no panorama e análise de uma das dimensões do processo.

Toma-se como premissa de uma escola com condições de qualidade aquela que reúne, além de outros predicativos, condições de gestão que influenciem positivamente nas demais dimensões da complexidade de uma instituição de ensino, privilegiando a relação com a comunidade e, consequentemente, a democracia nas escolas com a participação de todos nos processos decisórios das instituições, além da construção de uma cultura de paz. 
Nesse sentido, o desenvolvimento desse trabalho, fundamentado em Souza (2007), Souza et al. (2005), Gouveia, Souza e Schneider (2011), Dourado (2000), Bezerra (2009), Dourado, Oliveira e Santos (2007), Dourado et al. (2006), Silva (2012), Gadotti (2014) e, em uma fração de resultados, da dissertação de mestrado de Silva (2017), pretende atingir dois objetivos: a) fundamentar a metodologia do Índice de Condições de Gestão, indicador parcial do Índice de Condições de Qualidade, trabalhados na dissertação supracitada, e; b) apresentar uma análise do panorama das condições de gestão das redes municipais do país, com recorte para as escolas que ofertam os anos iniciais do Ensino Fundamental, com base nos dados de contexto provenientes dos questionários do diretor(a) da edição de 2013 da Prova Brasil.

Como metodologia de análise dos resultados, utilizou-se duas vertentes: a) agregar os resultados municipais por estado e; b) investigar a desigualdade intra e interestadual em termos de condições de gestão.

Os resultados indicaram grande desigualdade em condições de gestão no país e, de forma mais acentuada que em outras dimensões mensuradas em outros indicadores parciais do Índice de Condições de Qualidade, analisadas em Silva (2017), grande desigualdade intraestadual. Para tal, esse trabalho dedica-se inicialmente à metodologia empregada, passando a analisar posteriormente o panorama das condições de gestão no país.

\section{O índice de condições de gestão: fundamentação e metodologia}

O Índice de Condições de Qualidade (ICQ) foi desenvolvido em um programa de pesquisa do Núcleo de Políticas Educacionais da Universidade Federal do Paraná, "Qualidade no ensino fundamental: uma leitura das condições de efetividade dos sistemas estaduais e municipais de ensino a partir de indicadores de financiamento, condições de oferta e resultados escolares". O objetivo do desenvolvimento do ICQ foi se constituir em uma ferramenta de auxílio para a avaliação da relação entre a política e a qualidade na educação, proveniente da necessidade de aprofundamento sobre a efetividade da ação pública, buscando maior compreensão entre investimento financeiro na educação, as condições de qualidade e o desempenho estudantil (GOUVEIA; SOUZA; SCHNEIDER, 2011).

O ICQ envolve três dimensões, traduzidas em indicadores parciais, descritos em Gouveia, Souza e Schneider (2011) e trabalhados no diálogo com a literatura acadêmica em Silva (2017). A fonte de informações para cada indicador parcial, Índice de Condições do Professor (ICP), Índice de Condições Materiais da Escola (ICME) e Índice de Condições de Gestão (ICP), foram os questionários de contexto da Prova Brasil de 2013, respondidos pelas 
professoras de Língua Portuguesa e Matemática das turmas de $5^{\circ} \mathrm{s}$ anos avaliadas, das aplicadoras da avaliação e das diretoras das escolas.

Para este trabalho, o recorte se dá no ICG, haja vista que, conforme discorrido anteriormente, o objetivo desse artigo é, com recorte para os anos iniciais do EF, analisar as condições de gestão do conjunto de escolas das redes municipais do país. Nesse sentido, o ICG, composto por 4 variáveis, é fomentado quantitativamente por 4 perguntas do questionário de contexto do diretor/a, quantificado entre 0 e 1, assim como o próprio ICG. Com maior peso para o salário do diretor, precedido da forma de provimento e dos conselhos de escola, o indicador parcial do ICQ, seguiu uma coerência metodológica de correlação com os resultados de proficiências da Prova Brasil, revisados em Silva (2017). O cálculo do ICG de cada rede municipal é obtido pela média das variáveis das escolas e, com esse valor numérico, calcula-se o indicador conforme formulação abaixo:

\section{$\mathrm{ICG}=\mathrm{V} 1 * 5+\mathrm{V} 2 * 2+\mathrm{V} 3 * 2+\mathrm{V} 4$

Onde:

V1 = Indicador de Salário do Diretor

V2 = Indicador de Forma de Provimento

V3 = Indicador de Conselho de Escola

V4 = Indicador de Projeto Político Pedagógico

Em descrição metodológica, a primeira variável do indicador, intitulada de Indicador de Salário do Diretor (V1), é baseada na questão n. 10, conforme quadro abaixo.

Quadro 1 - Perguntas que compõem a variável Indicador de Salário do Diretor (V1) com base nos questionários de contexto do diretor da Prova Brasil de 2013

\begin{tabular}{|c|c|c|}
\hline Variável & Identificação da Questão & Pergunta \\
\hline V1 & Q10 & $\begin{array}{c}\text { Como diretor, qual é, aproximadamente, o } \\
\text { seu salário bruto? (Com adicionais, se } \\
\text { houver) }\end{array}$ \\
\hline
\end{tabular}

Fonte: Questionários de contexto da Prova Brasil (2013)

Assim, a tabela a seguir descreve as 11 alternativas de resposta e suas respectivas conversões numéricas. 
Tabela 1 - Respostas quantificadas em relação a variável V1 do ICG - 2013

\begin{tabular}{|c|c|c|}
\hline Alternativa & Texto & Quantificação \\
\hline $\mathrm{A}$ & Até $\mathrm{R} \$ 678,00$ & 0,1 \\
\hline $\mathrm{B}$ & Entre $\mathrm{R} \$ 679,00$ e $\mathrm{R} \$ 1.017,00$ & 0,13 \\
\hline $\mathrm{C}$ & Entre $R \$ 1.018,00$ e $R \$ 1.356,00$ & 0,18 \\
\hline $\mathrm{D}$ & Entre $\mathrm{R} \$ 1.357,00$ e $\mathrm{R} \$ 1.695,00$ & 0,23 \\
\hline $\mathrm{E}$ & Entre $\mathrm{R} \$ 1.696,00$ e $\mathrm{R} \$ 2.034,00$ & 0,28 \\
\hline $\mathrm{F}$ & Entre $\mathrm{R} \$ 2.035,00$ e $\mathrm{R} \$ 2.373,00$ & 0,33 \\
\hline $\mathrm{G}$ & Entre $\mathrm{R} \$ 2.374,00$ e $\mathrm{R} \$ 2.712,00$ & 0,38 \\
\hline $\mathrm{H}$ & Entre $R \$ 2.713,00$ e $R \$ 3.390,00$ & 0,45 \\
\hline I & Entre $\mathrm{R} \$ 3.391,00$ e $\mathrm{R} \$ 4.746,00$ & 0,6 \\
\hline $\mathrm{J}$ & Entre $R \$ 4.747,00$ e $R \$ 6.780,00$ & 0,85 \\
\hline $\mathrm{K}$ & $\mathrm{R} \$ 6.781,00$ ou mais & 1 \\
\hline
\end{tabular}

Fonte: Questionários de Contexto da Prova Brasil (2013). Dados trabalhados pelos autores.

O salário de qualquer profissional é um atrativo para o desenvolvimento de seu trabalho. No cargo de diretor (a) não é diferente. Entretanto, pela metodologia, maiores salários culminam em maior impacto numérico para o ICG. Dourado, Oliveira e Santos (2007) ressaltam a importância do papel do dirigente enquanto um elemento de efetivação das estratégias que visam a participação democrática da comunidade nos processos decisórios como conselhos escolares, associações de pais e mestres, entre outros, caracterizando o diretor/a com um papel fundamental na efetivação dos instrumentos de participação na gestão democrática e as condições de trabalho.

Todavia, reconhece-se que a problematização em torno do salário do diretor/a como uma variável do ICG precisa de maior fundamentação em termos empíricos e qualitativos, investigação que não compõe os objetivos deste trabalho. Aspectos como o salário do diretor/a em um viés de ação/coptação política, designando um coordenador local da gestão política, e o mesmo como condição de qualidade do seu trabalho e não da gestão são alguns pontos que necessitam de aprofundamento.

A segunda variável do ICG é intitulada de Indicador de Forma de Provimento (V2). O quadro abaixo descreve a questão que fomenta a variável. 
Quadro 2 - Perguntas que compõem a variável Indicador de Forma de Provimento (V2) com base nos questionários de contexto do diretor da Prova Brasil de 2013

\begin{tabular}{|c|c|c|}
\hline Variável & Identificação da Questão & Pergunta \\
\hline V2 & Q14 & $\begin{array}{c}\text { Você assumiu a direção desta escola por } \\
\text { meio de: }\end{array}$ \\
\hline
\end{tabular}

Fonte: Questionários de contexto da Prova Brasil (2013).

Mensurada diretamente pela alternativa assinalada, a V2 do ICG é composta de sete alternativas. A tabela abaixo descreve a conversão numérica das respostas.

Tabela 2 - Respostas quantificadas em relação a variável V2 do ICG - 2013

\begin{tabular}{ccc}
\hline Alternativa & Texto & Quantificação \\
\hline A & Concurso público apenas & 0,5 \\
B & Eleição apenas & 1 \\
C & Indicação apenas & 0,25 \\
D & Processo seletivo apenas & 0,5 \\
E & Processo seletivo e Eleição & 0,75 \\
F & Processo seletivo e Indicação & 0,3 \\
G & Outra forma & 0 \\
\hline
\end{tabular}

Fonte: Questionários de Contexto da Prova Brasil (2013). Dados trabalhados pelos autores.

A crítica ao processo de indicação política de diretores escolares ensejou a busca de mecanismos alternativos, como o concurso público e as eleições diretas. Bezerra (2009), endossada por Dourado (2000), discorre que, no que diz respeito à administração da educação e a luta contra o clientelismo e o autoritarismo, a eleição de diretores é um passo importante, consolidada como uma das principais bandeiras na luta pela democratização do ensino. Enfatizando a eleição direta de dirigentes, a autora destaca que a ação democrática de escolha do diretor beneficia a escola em vários aspectos, "tendo em vista o aperfeiçoamento do trabalho e das relações no interior da instituição, melhorando especialmente a qualidade do ensino" (BEZERRA, 2009). Souza (2007, p. 189) ressalta que "o diretor eleito não é, por natureza do processo seletivo, mais compromissado com a educação pública de qualidade para todos (as)". Todavia, o autor salienta que "a eleição é o instrumento que, potencialmente, 
permite à comunidade escolar controlar as ações do dirigente escolar no sentido de levá-lo a se comprometer com esse princípio".

Ainda que não se tenha clara evidência de que a eleição de dirigentes se aproxime com condições de qualidade na gestão do que outras formas de provimento, é fato que ela dialoga com a gestão democrática, vista pela metodologia como a maior aproximação de um conceito de gestão voltado à melhoria da qualidade do ensino. A V3 do ICG é denominada de Indicador de Conselho de Escola. O quadro 3 descreve a questão fomentadora da variável.

Quadro 3 - Perguntas que compõem a variável Indicador de Conselho de Escola (V3) com base nos questionários de contexto do diretor da Prova Brasil de 2013

\begin{tabular}{|c|c|c|}
\hline Variável & $\begin{array}{c}\text { Identificação da } \\
\text { Questão }\end{array}$ & Pergunta \\
\hline V3 & Q29 & $\begin{array}{r}\text { O Conselho Escolar é um colegiado geralmente } \\
\text { constituído por representantes da escola e da } \\
\text { comunidade que tem como objetivo acompanhar as } \\
\text { atividades escolares. Neste ano, quantas vezes se reuniu } \\
\text { o Conselho Escolar? }\end{array}$ \\
\hline
\end{tabular}

Fonte: Questionários de contexto da Prova Brasil (2013).

A tabela 3 elenca as cinco possibilidades de resposta e as respectivas quantificações da variável.

Tabela 3 - Respostas quantificadas em relação a variável V3 do ICG - 2013

\begin{tabular}{ccc}
\hline Alternativa & Texto & Quantificação \\
\hline A & Não existe Conselho Escolar & 0 \\
B & Nenhuma vez & 0 \\
C & Uma vez & 0,25 \\
D & Duas vezes & 0,5 \\
E & Três vezes ou mais & 1
\end{tabular}

Fonte: Questionários de Contexto da Prova Brasil (2013). Dados trabalhados pelos autores.

Com base no Art. 14 da LDB, "Os sistemas de ensino definirão as normas da gestão democrática do ensino público na educação básica, de acordo com as suas peculiaridades". No inciso II do referido artigo destaca-se a "participação das comunidades escolar e local em 
conselhos escolares ou equivalentes". É um dos instrumentos de gestão democrática elencados por Souza et al (2005) e discutido na literatura como dimensão importante ao se pensar gestão democrática do ensino. Dourado et al. definem que,

O Conselho Escolar configura-se, portanto, como órgão de representação da comunidade escolar e, desse modo, visa à construção de uma cultura de participação, constituindo-se em espaço de aprendizado do jogo político democrático e de formação político-pedagógica. Por essa razão, a consolidação dos Conselhos Escolares implica buscar a articulação efetiva entre os processos pedagógicos, a organização da escola e o financiamento da educação e da escola propriamente dita (DOURADO et al., 2006, p. 80).

Enfatiza-se a importância dos conselhos de escola na medida em que "a escola necessita desenvolver formas democráticas de organização, gestão e funcionamento, dando atenção à melhoria dos processos formativos, à utilização transparente dos recursos e à melhoria das relações de trabalho" (DOURADO et al., 2006, p. 78). Para Alves (2011) a existência dos conselhos de escola garante "a participação direta e indireta de todos os segmentos da comunidade em todos os âmbitos da escola, permitindo integração escolacomunidade", enfatizando que o colegiado dá lugar à "cidadania, autonomia, participação comunitária, ao aprendizado político e social, ao diálogo, à democratização e reivindicação coletiva”.

O limite da avaliação dessa variável se dá na impossibilidade de avaliar a efetividade das ações e decisões discutidas no colegiado. O que é possível, com tais alternativas, é aproximar, ainda que de forma panorâmica, a existência (principalmente) e a frequência de reunião do colegiado.

A quarta variável do ICG, denominada de Indicador de Projeto Político Pedagógico (V4), é descrita pelo quadro abaixo.

Quadro 4 - Perguntas que compõem a variável Indicador de Projeto Político Pedagógico (V4) com base nos questionários de contexto do diretor da Prova Brasil de 2013

\begin{tabular}{|c|c|c|}
\hline Variável & Identificação da Questão & Pergunta \\
\hline V4 & Q32 & $\begin{array}{c}\text { Neste ano e nesta escola, como se deu a } \\
\text { elaboração do Projeto Pedagógico? }\end{array}$ \\
\hline
\end{tabular}

Fonte: Questionários de contexto da Prova Brasil (2013).

As oito alternativas de resposta da questão são quantificadas de acordo com a tabela abaixo. 
Tabela 4 - Respostas quantificadas em relação a variável V4 do ICG - 2013

\begin{tabular}{ccc}
\hline Alternativa & Texto & Quantificação \\
\hline A & Não sei como foi desenvolvido & 0,1 \\
B & Não existe Projeto Pedagógico & 0 \\
C & Utilizando-se um modelo pronto, sem discussão & 0,1 \\
& com a equipe escolar & \\
D & Utilizando-se um modelo pronto, mas com & 0,2 \\
& discussão com a equipe escolar \\
E & Utilizando-se um modelo pronto, porém com & 0,2 \\
F & adaptações, sem discussão com a equipe escolar & \\
& Utilizando-se um modelo pronto, porém com & 0,33 \\
G & adaptações e com discussão com a equipe escolar & \\
& Elaborou-se um modelo próprio, mas não houve & 0,5 \\
H & Elaborou-se um modelo próprio e houve discussão & 1
\end{tabular}

Fonte: Questionários de Contexto da Prova Brasil (2013). Dados trabalhados pelos autores.

No art. 12 da LDB é estabelecido às unidades escolares a incumbência de construir sua proposta pedagógica, constituindo-se elemento fundamental para direcionar as ações da escola e fundamentar as práticas educativas. Além disso, o art. 13 orienta que a construção da proposta pedagógica da escola tenha a participação dos docentes em sua discussão, elementos que dão ao documento um caráter autônomo na dimensão da escola e democrático em relação aos profissionais da instituição.

Elencado como um princípio da gestão democrática (Art. 14, inciso I), a construção coletiva da proposta pedagógica compreende questão importante no pensamento da gestão democrática como princípio do ensino proposto e, consequentemente, nas condições de qualidade da educação. Dourado et al (2006, p. 72) indicam que "a elaboração do projeto político-pedagógico implica um repensar constante no dia-a-dia da escola, seus processos culturais e a forma como ela se encontra estruturada".

Bezerra (2009) alia o fato da dificuldade do estabelecimento de uma cultura de gestão democrática ao Projeto Político Pedagógico (PPP) quando discorre que a gestão voltada à democracia acaba por se constituir "numa ação, numa prática na escola, associada à 
elaboração do projeto político-pedagógico das escolas e à implantação de conselhos de escola que efetivamente influenciem na gestão escolar em seu todo”.

Silva (2012) caracteriza o PPP como um documento físico, oficial e legal, com objetivo de descrever objetivos e, eventualmente, métodos e procedimentos da instituição. Além disso, ele norteia a prática de funcionamento da instituição pela avaliação de suas condições peculiares e planejamento de ações, além do esforço de agentes da instituição quanto à organização intraescolar, seus valores e princípios. O alerta do autor se dá na efetividade da utilização desse documento, que por vezes é inutilizado, tendo seu conteúdo repetido ano após ano, sem nenhuma discussão ou criticidade acerca do documento e de sua função dentro da instituição de ensino.

O limite do dado na V4 do ICG se dá na medida que não se avalia com clara evidência, qualitativamente falando, a forma de construção da proposta. Portanto a informação mais relevante na aproximação com a realidade se dá na existência ou não da proposta, apesar da pergunta de base questionar quanto à sua construção.

$\mathrm{O}$ indicador parcial foi pensado de forma que suas variáveis, em particular V2, V3 e V4, teriam maior quantificação à medida que se aproximassem de práticas de maior envolvimento dos profissionais da educação e da comunidade escolar, conforme citado anteriormente, haja vista que a gestão democrática dos sistemas de ensino é entendida como "uma das dimensões fundamentais que possibilitam o acesso à educação de qualidade", à formação para a cidadania e como "princípio da educação nacional" da elaboração de "planos de desenvolvimento educacional" e de "projetos político-pedagógicos participativos" (BRASIL, 2011, p. 59-60). Portanto, entende-se que a gestão da escola é um de seus pilares para tais concretizações.

Todas as questões que permeiam o ICG, a remuneração do diretor, existência e frequência de reunião dos conselhos de escola, construção coletiva de proposta pedagógica e participação da comunidade, professores e funcionários nas decisões, são aspectos reconhecidos pela literatura (SOUZA, 2007) como pontos importantes para possibilitar a elevação do padrão de qualidade de uma escola. Ademais, esses itens compõem bases de dados passíveis de serem lidas na busca por um panorama da gestão escolar. Isto é, trata-se de aspectos reconhecidamente influenciadores da qualidade escolar e que estão, ainda que parcialmente, à disposição da comunidade acadêmica.

\section{Análise das condições de gestão no Brasil}


Para o desenvolvimento da pesquisa foram obtidos dados de 4600 redes municipais, com base nos questionários de contexto do diretor/a da Prova Brasil em 2013. A abrangência de escolas foi pouco mais de $21 \%$, indicativo de algumas redes municipais representadas com um percentual de escolas menor que a metade do total existente. Todavia, trata-se de um quantitativo que permite apontar alguns indícios e evidências acerca do tema proposto. Em análise inicial do ICG, a tabela abaixo apresenta dados estatísticos nacionais em relação ao indicador.

Tabela 5 - Análise quantitativa do ICG no Brasil - 2013

\begin{tabular}{|c|c|c|c|c|c|}
\hline $\begin{array}{l}\text { Discriminação } \\
\text { dados }\end{array}$ & V1 & $\mathrm{V} 2$ & V3 & V4 & ICG \\
\hline Média & 0,38 & 0,36 & 0,60 & 0,53 & 0,43 \\
\hline Mediana & 0,36 & 0,25 & 0,63 & 0,50 & 0,42 \\
\hline Desvio padrão & 0,14 & 0,23 & 0,33 & 0,25 & 0,13 \\
\hline Mínimo & 0,10 & 0 & 0 & 0 & 0,11 \\
\hline Máximo & 1,00 & 1,00 & 1,00 & 1,00 & 0,92 \\
\hline
\end{tabular}

Fonte: Dados trabalhados pelos autores (2017).

Os dados numéricos apontam para uma variação de resultados, em particular nas variáveis de gestão democrática do ICG. A análise de medianas em relação às médias indicam na V2 que grande parte das redes municipais não tem na eleição direta de dirigentes escolares a forma de provimento padrão, assim como V3 e V4, que caracterizaram as práticas democráticas nas escolas com pouca efetividade. Em relação ao salário, as variações são bem menores, panorama que reflete em um ICG com desvio padrão alto, mas bem menor que as demais variáveis, no caso da V1. O histograma abaixo distribui os casos por frequência em todo intervalo numérico do indicador. 
Gráfico 1: Histograma de frequência do ICG no Brasil - 2013

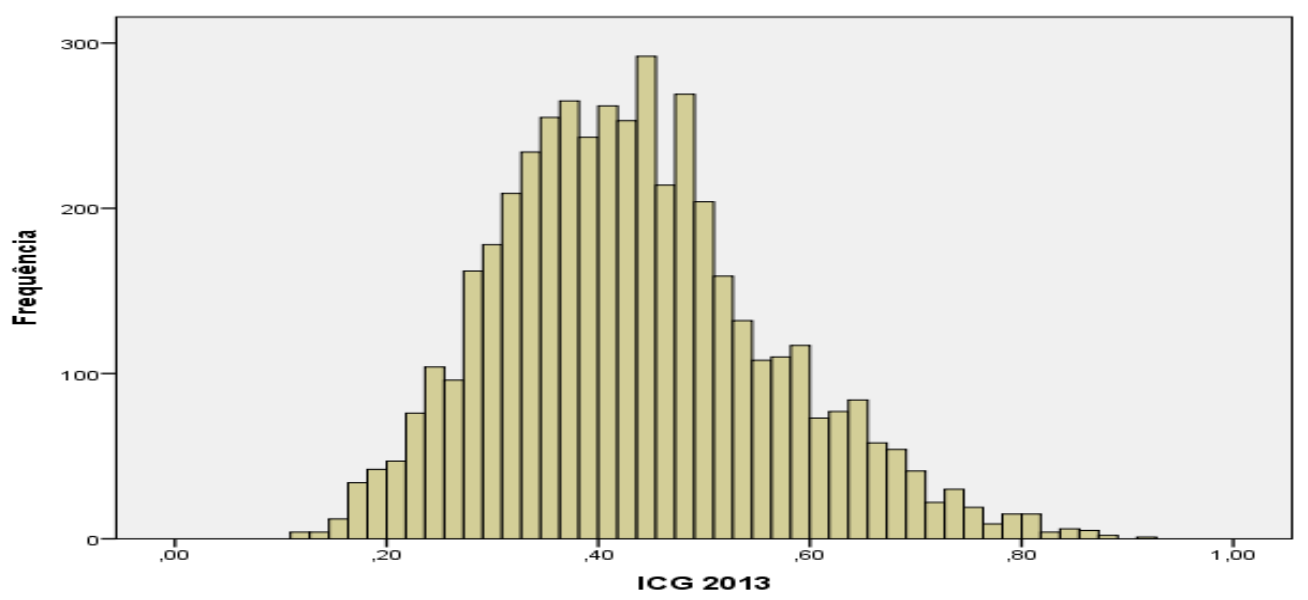

Fonte: Dados trabalhados pelos autores.

Mais de $90 \%$ dos casos concentram-se 0,2 e 0,6. Há de se considerar que o salário do diretor/a compõe 50\% do ICG e, sua média de 0,384, indica uma tendência de diminuir o resultado numérico. Para isso, fez se necessário um aprofundamento sobre o comportamento de cada variável a nível nacional. Primeiramente, o gráfico 2 trabalha o histograma da variável V1, o Indicador de Salário do Diretor.

Gráfico 2: Histograma de frequência do Indicador de Salário do Diretor do ICG no Brasil 2013

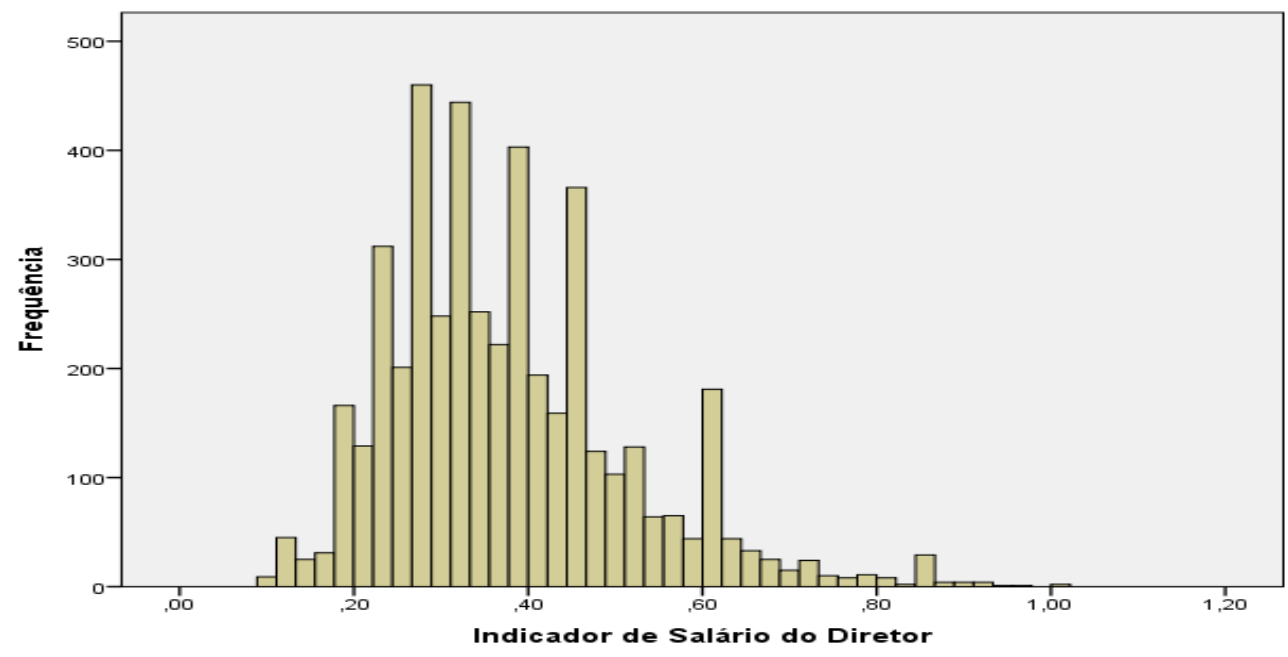

Fonte: Dados trabalhados pelos autores.

Percebe-se a maior concentração dos resultados numéricos entre 0,2 e 0,5, que indica uma faixa salarial entre $\mathrm{R} \$ 1.500,00$ e $\mathrm{R} \$ 4.000,00$ em aproximadamente $90 \%$ dos casos. O 
histograma a seguir apresenta os resultados da V2 do ICG, o Indicador de Forma de Provimento, já descrito anteriormente.

Gráfico 3: Histograma de frequência do Indicador de Forma de Provimento do ICG no Brasil $-2013$

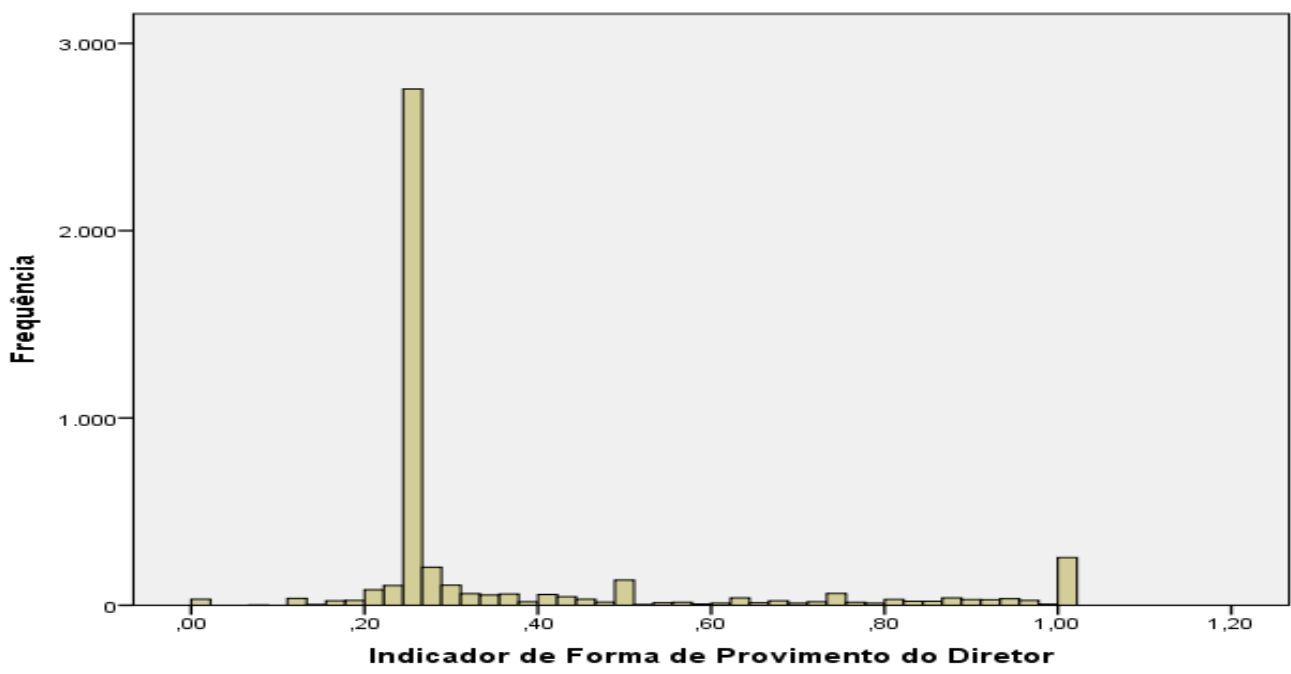

Fonte: Dados trabalhados pelos autores.

Os mais de 2500 casos indicam que a grande maioria das diretoras, agrupadas por redes municipais, tem seu provimento por indicação. A base de dados da pesquisa apresentou apenas 255 redes municipais com suas diretoras eleitas em todas suas escolas municipais, ou seja, apenas 5,54\% dos casos. As redes municipais do Paraná, Mato Grosso, Goiás e Acre têm os maiores percentuais de eleição de dirigentes, com 21,2\%, 44\%, $14 \%$ e $19 \%$ respectivamente. Os dados evidenciam a necessidade de trabalhar a democracia nas escolas a partir da eleição de seu dirigente, que não é efetivada nas redes municipais do país. O gráfico a seguir trabalha com a variável V3, o Indicador de Conselho de Escola.

Gráfico 4: Histograma de frequência do Indicador de Conselho de Escola do ICG no Brasil 2013 


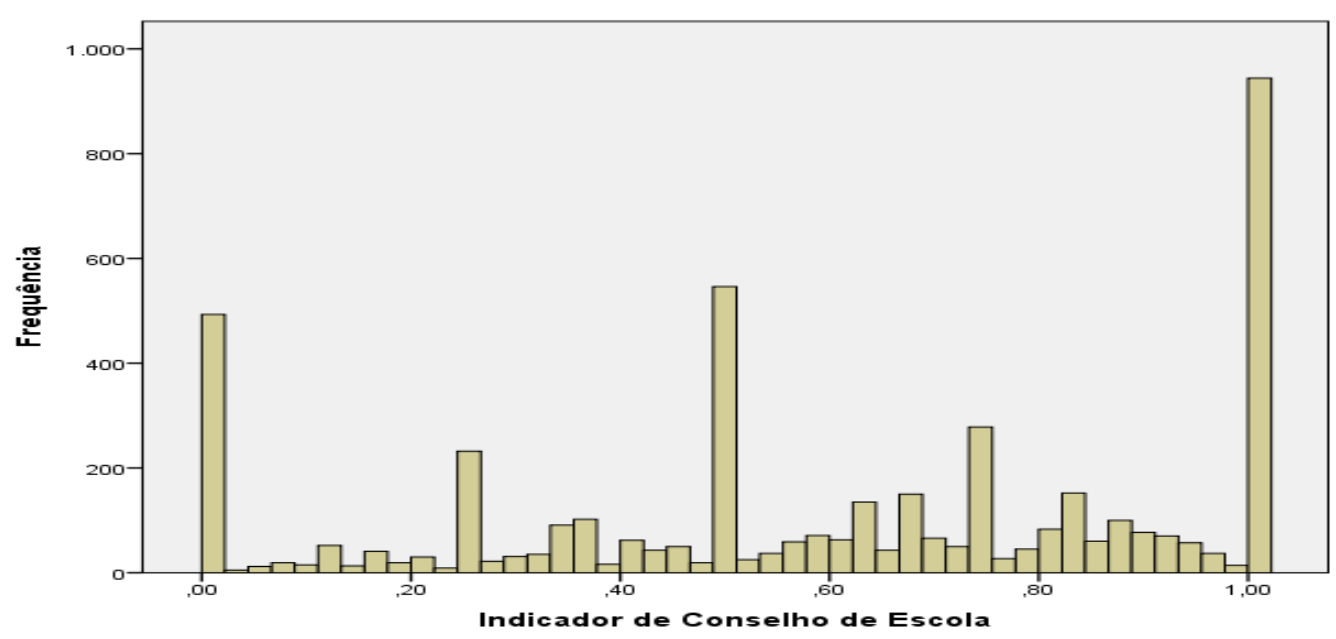

Fonte: Dados trabalhados pelos autores.

Pouco mais de 550 casos evidenciam a ausência de conselhos de escola em suas instituições nas redes municipais. Em contrapartida, o conjunto de escolas de pouco menos de 1000 redes municipais da amostra reuniu mais de três vezes o Conselho durante o último ano, na ocasião em que o questionário foi respondido. Observou-se também que pouco menos de 600 casos que reuniram o colegiado apenas uma vez no período referido. Sendo assim, o panorama nacional evidenciou a necessidade de trabalhar a gestão democrática na dimensão existência e efetividade do colegiado.

Os dados da pesquisa apontam que, em relação à reunião ao menos uma vez no ano do referido colegiado, destacaram-se as redes municipais do estado do Mato Grosso, com quase $60 \%$ de suas redes municipais da amostra com reunião mais frequente de seus Conselhos de Escola. Maranhão, Bahia, Roraima, Acre, Pará, Pernambuco e Rio de Janeiro tiveram resultados bastante incipientes na dimensão analisada pela V3, haja vista que menos de $10 \%$ de suas redes de ensino tiveram em seus colegiados alguma frequência de reunião.

Prosseguindo na análise das variáveis, o gráfico abaixo distribuiu por frequência a V4 do ICG, o Indicador de Projeto Político Pedagógico. 
Gráfico 5: Histograma de frequência do Indicador de Projeto Político Pedagógico do ICG no Brasil - 2013

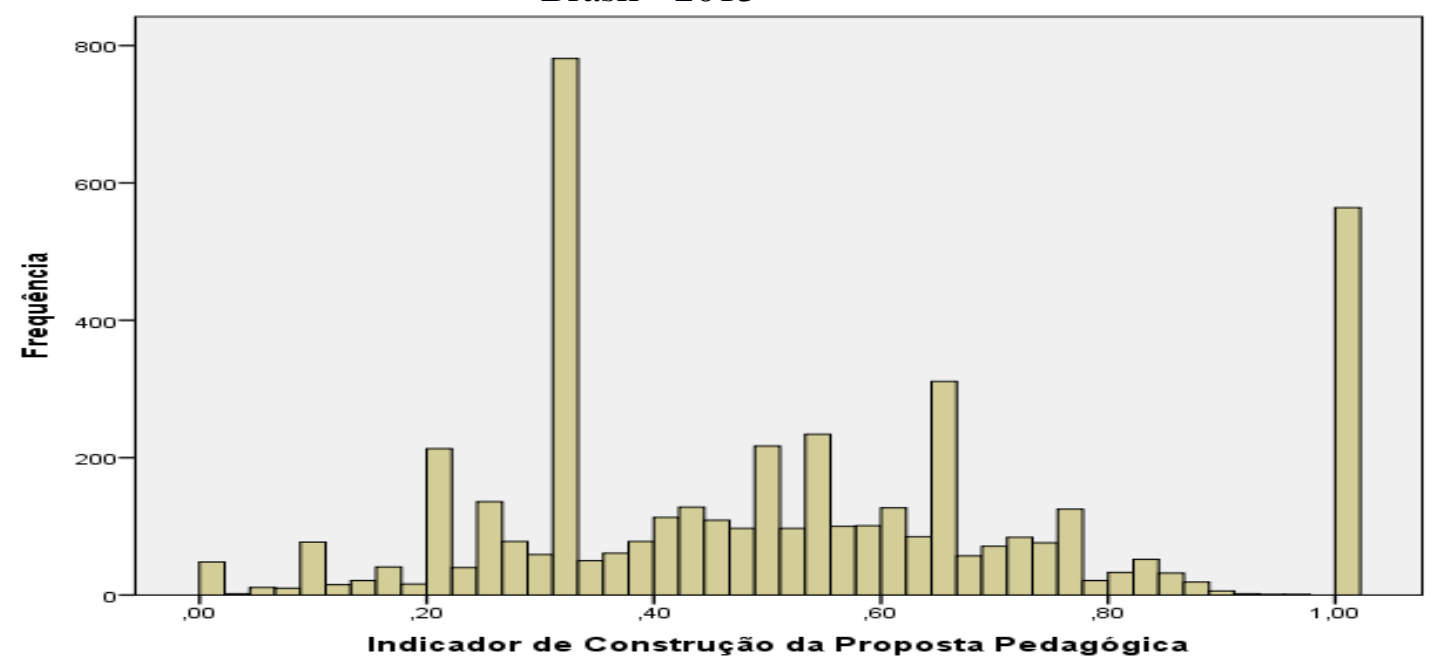

Fonte: Dados trabalhados pelos autores.

Em panorama similar à V2 e V3, pouco mais de 550 casos declararam que realizaram a construção do PPP elaborando um modelo próprio em discussão com a equipe escolar, o que a metodologia do ICQ e a literatura acadêmica entendem como prática aproximada com uma gestão democrática. Em boa parte dos casos, indica a utilização de um modelo pronto, mas, com adaptações e discussão com a equipe da escola. Nos demais casos, distribuídos por todo intervalo, evidenciaram a diversidade de metodologias na construção da proposta nas escolas, haja vista que o indicador foi gerado pelas médias dos resultados por escola, com uma mensuração por município.

Os valores abaixo de 0,3 indicam uma tendência de escolas sem proposta pedagógica ou de desconhecimento da sua forma de construção por parte da diretora. A base de dados dessa pesquisa indicou que as redes municipais dos estados do Acre, Piauí e Roraima tiveram maiores percentuais de seus casos no intervalo supracitado. Outros estados como Alagoas, Amapá, Maranhão, Rondônia, e Sergipe também se destacaram com altos percentuais de suas redes municipais nesse perfil.

Trabalhadas individualmente suas variáveis, o gráfico a seguir exibe os resultados agregados por estado do indicador das redes municipais analisadas.

Gráfico 6: Resultados das médias do ICG das redes municipais agregadas por estado - 2013 


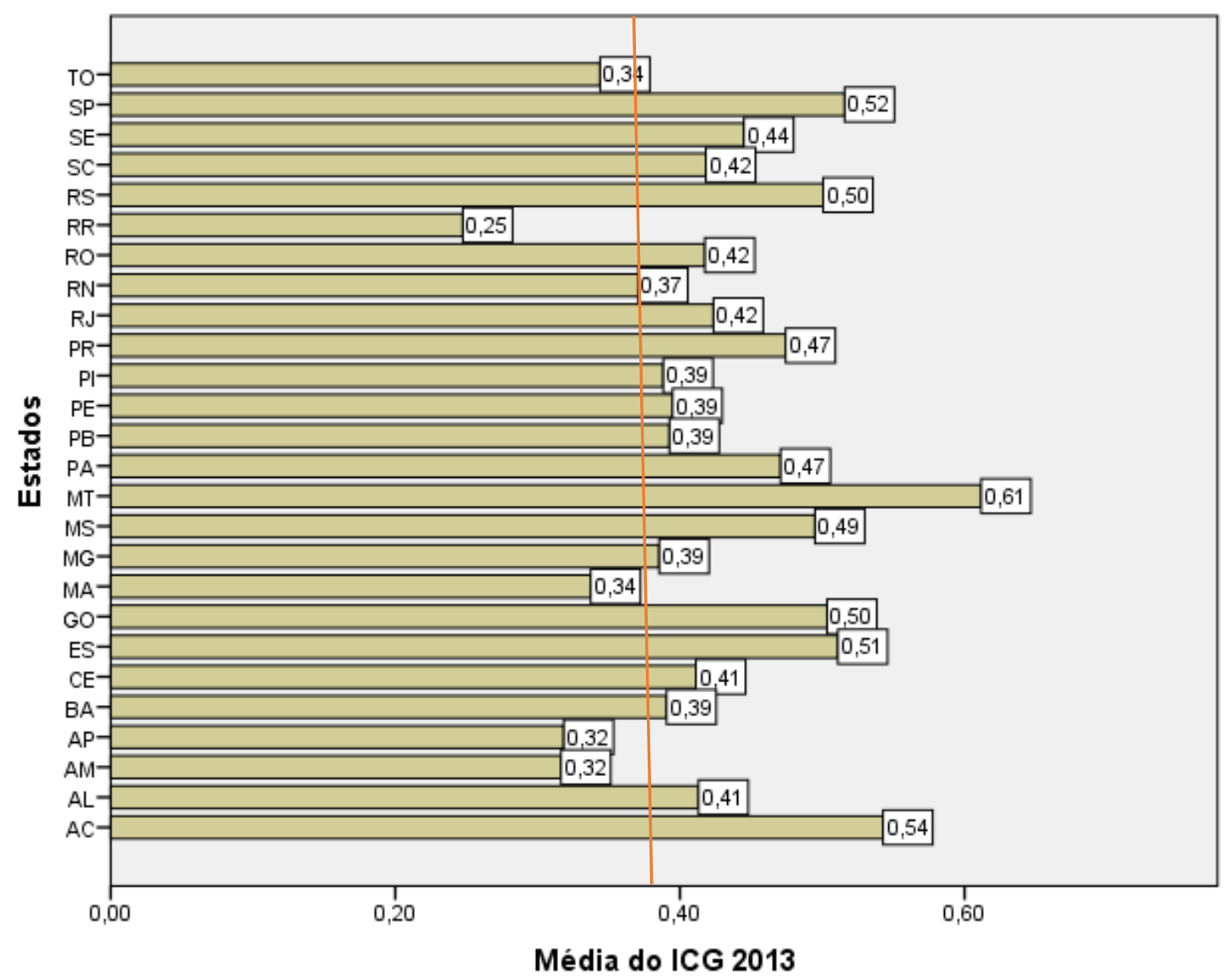

Fonte: Dados trabalhados pelos autores.

Agregando as redes municipais por estado, evidenciam-se as desigualdades regionais. No caso do ICG, uma das características que evidencia a variação de resultados é a diferença entre o valor máximo e mínimo. A linha em vermelho, balizando a média do indicador no país, auxilia a visualizar a distância de alguns resultados do valor médio, caracterizando a diversidade de Índices de Condições de Gestão no Brasil.

\section{Panorama das condições de gestão e desigualdade intraestadual}

Trabalhando outros elementos para entender o panorama das condições de gestão no país, o gráfico a seguir possibilita analisar o impacto real de cada variável nos resultados de ICG, observando o quanto o salário de diretor, $50 \%$ do valor do indicador, influencia na média nas condições de gestão das redes municipais agregadas por estado. $\mathrm{O}$ valor real do ICG é obtido dividindo o quantitativo do gráfico por 10.

Gráfico 7: Variáveis do ICG agregadas por estado no Brasil - 2013 


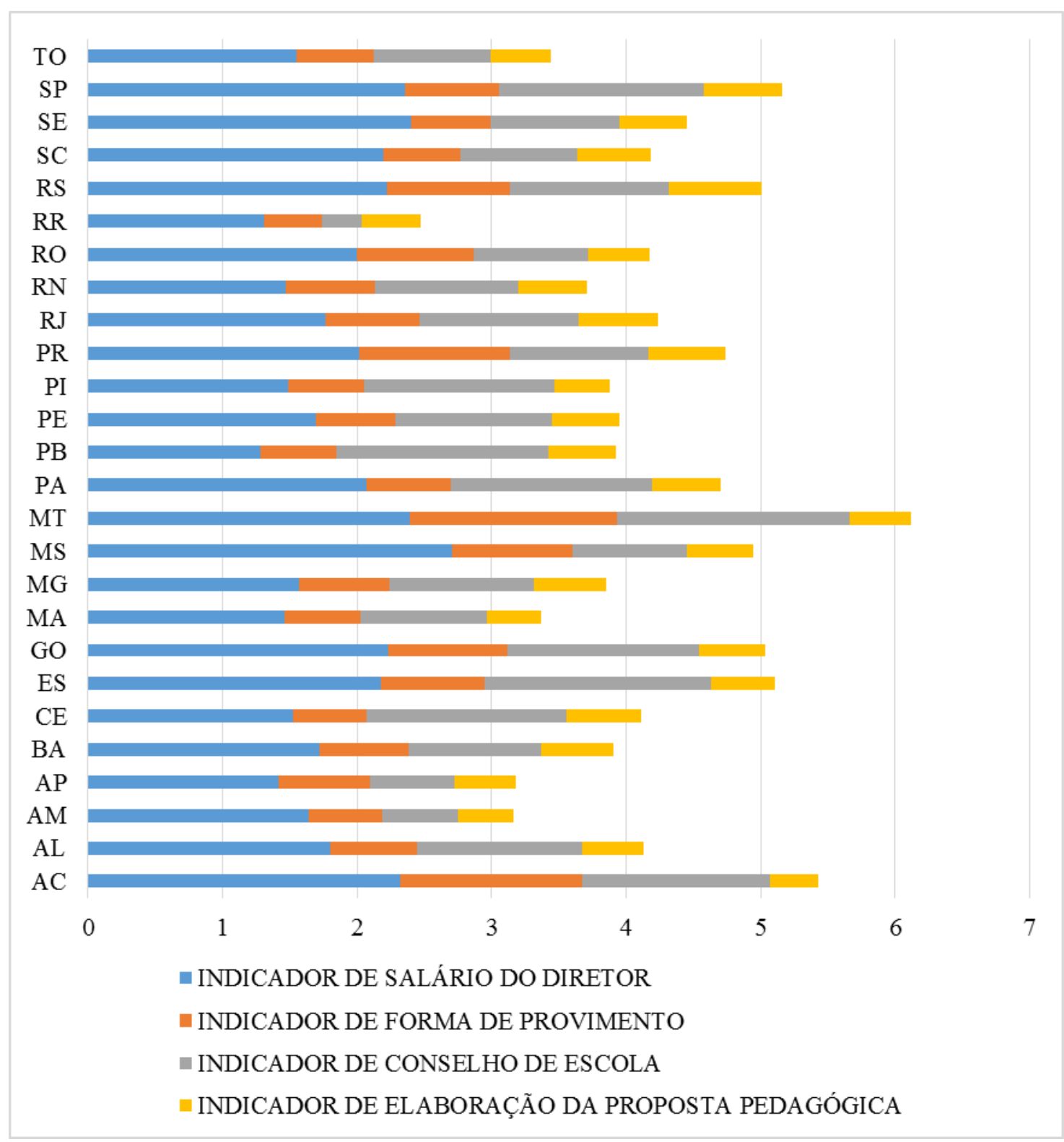

Fonte: Dados trabalhados pelos autores.

Em impactos proporcionais, os salários de diretores e diretoras deveriam significar para o indicador $50 \%$ de seu valor. Entretanto, 21 estados têm em tal variável impacto menor. Apenas nas redes municipais dos estados do Amazonas, Mato Grosso do Sul, Roraima, Santa Catarina e Sergipe, o salário do diretor (a) tem impacto maior que 50\%, ainda que Amazonas e Roraima estejam entre as piores condições de gestão do país. Tal dado evidencia que, para estes dois casos, o maior impacto dos salários não reverbera em melhores ICG. Ilustrando o panorama das condições de gestão do país, o mapa abaixo, com base em uma legenda de escala, organiza os dados e auxilia na visualização do respectivo panorama. 
Mapa 1: Panorama das médias do ICG agregadas por estado no Brasil - 2013

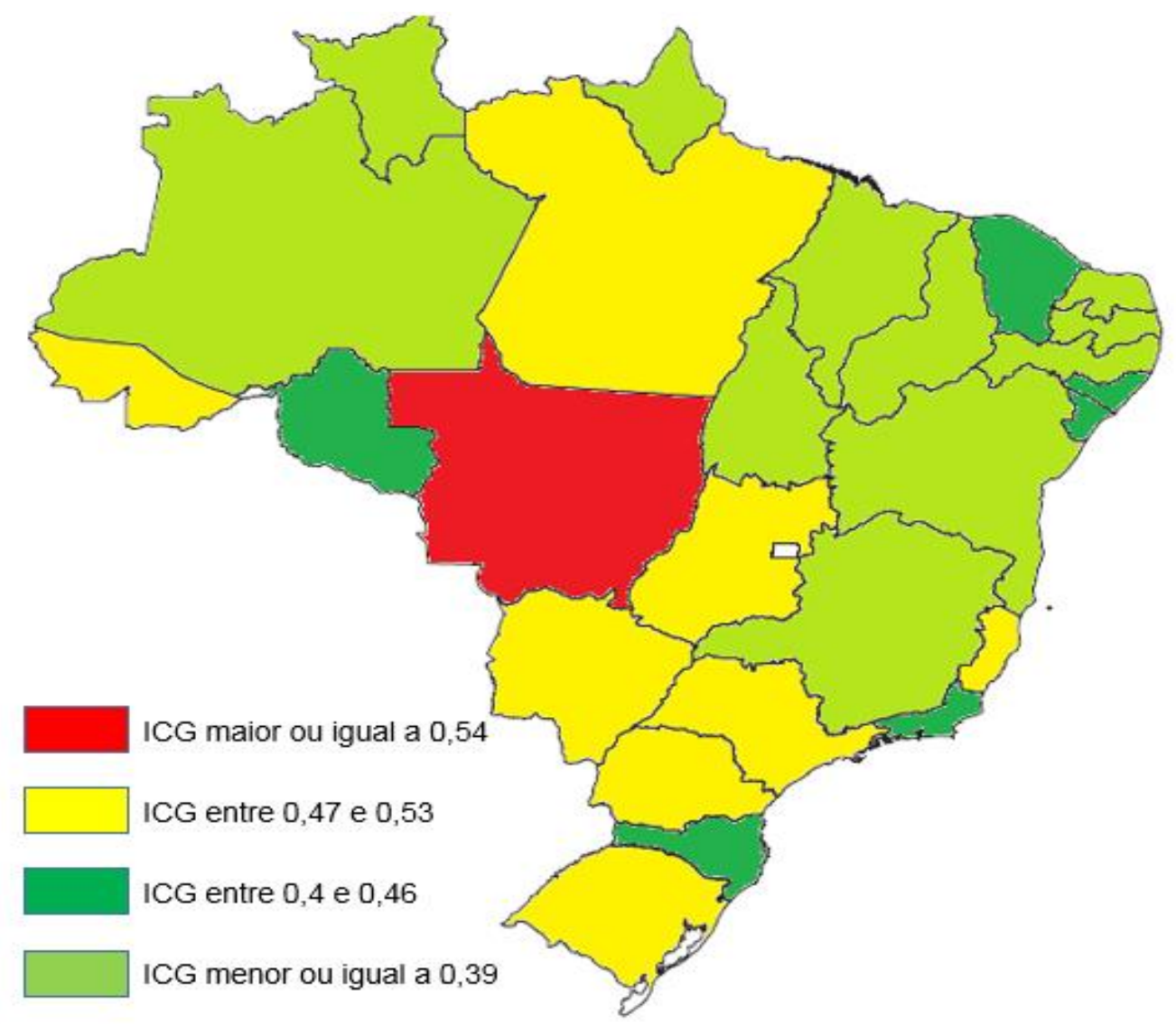

Fonte: Dados trabalhados pelos autores.

Apesar dos melhores resultados se concentrarem nas regiões Sul, Sudeste e CentroOeste, com destaque para o conjunto das redes municipais do estado do Mato Grosso, Santa Catarina, Rio de Janeiro e Minas Gerais aparecem com resultados similares aos da Região Norte e Nordeste. Com exceção do estado do Pará e o Acre (este, pela valorização do salário do diretor/a), o cenário nas regiões Norte e Nordeste é de baixas condições de gestão.

Os dados supracitados indicam possibilidades de investigação. Primeiramente, nos estados do Mato Grosso do Sul, Santa Catarina e Sergipe houve maiores indícios de diretores/as com maiores salários, possivelmente por uma política educacional de valorização ou carreira específica, juntamente com São Paulo, Rio Grande do Sul, Goiás e Espírito Santo. Considerando as variáveis Indicador de Forma de Provimento, Indicador de Conselho de Escola e Indicador de Construção da Proposta Pedagógica, as redes municipais dos estados do Mato Grosso, Acre, Espírito Santo, Goiás, São Paulo, Rio Grande do Sul, Paraná, Paraíba, Pará e Ceará, apresentaram melhores indicadores nas políticas de gestão democrática, em 
contraposição a Roraima, Amapá, Amazonas, Tocantins, Maranhão, Santa Catarina, Sergipe, Rondônia, Bahia e Rio Grande do Norte.

Em outra análise, o gráfico a seguir busca um panorama dos resultados do ICG dentro do conjunto das redes municipais em cada estado.

Gráfico 8: Distribuição e dispersão dos resultados do ICG das redes municipais por estado -

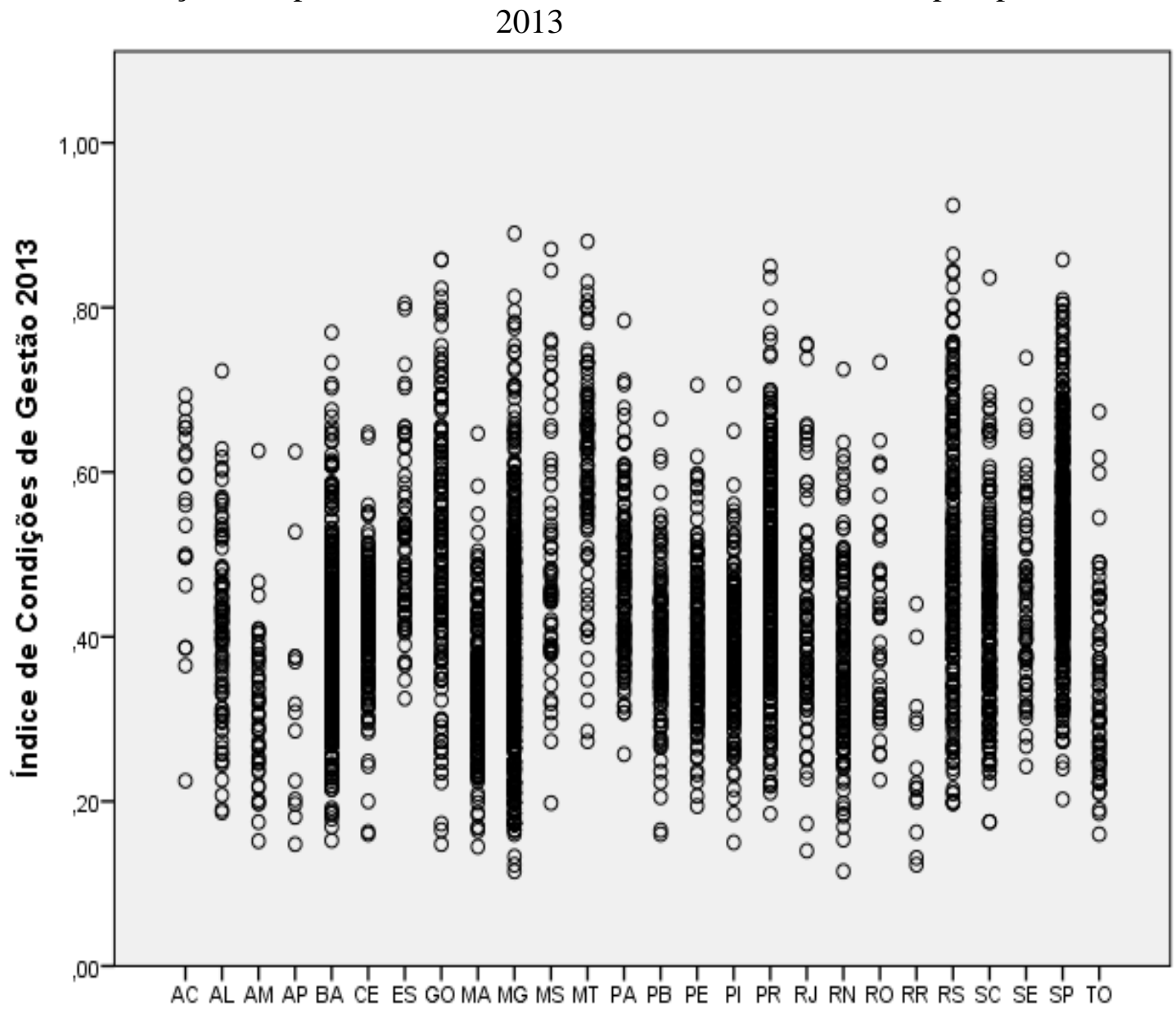

Estados

Fonte: Dados trabalhados pelos autores.

É perceptível a dispersão dos casos em relação ao ICG, haja vista que os resultados se distribuem por grande parte do intervalo de 0 a 1 . Todavia, os estados do Tocantins, Piauí, Pernambuco, Pará, Ceará e Amazonas apresentaram menores dispersões em relação aos demais, o que indica que, apesar de tais conjuntos de redes municipais supracitados terem um cenário de maior dispersão, em praticamente todos os estados o cenário de variação dos resultados do ICG é alto. 


\section{Considerações finais}

Divergindo do senso comum, a equipe diretiva não é o coração da escola. A relação entre professores e alunos sempre será o ponto principal e as ações da escola (inclusive o modelo de gestão) são voltadas para o aprimoramento da mesma e a melhoria da qualidade do ensino (SOUZA et al., 2005). Todavia, a perspectiva dessa pesquisa entende que a gestão do ensino é dimensão fundamental na premissa de uma instituição de ensino pública com condições de ofertar uma educação de qualidade.

Nesse sentido, a análise dos resultados evidenciou maior distância nas condições de gestão do estado do Mato Grosso, seguidos do Acre, São Paulo, Espírito Santo, Goiás e Rio Grande do Sul. Pela formulação do ICG, as redes municipais que tenderam a pagar melhores salários tiveram seu ICG mais alto, como São Paulo, Mato Grosso, Mato Grosso do Sul, Espírito Santo e Acre, ainda que as demais variáveis acompanhem a referida variável nos bons resultados. Em contraposição, os estados de Roraima, Amapá, Amazonas, Maranhão e Tocantins tiveram ICG menores ou iguais a 0,35, todos da Região Norte e Nordeste do país.

O estudo realizado por variável e por indicador parcial permitiu observar algumas peculiaridades importantes para pensar as condições de qualidade das escolas e, principalmente, a efetividade da ação (ou falta de) da política educacional em termos de condições de gestão. O cenário é de distância entre a efetividade dos instrumentos de gestão democrática nas escolas das redes municipais do país, evidenciada pelas análises das variáveis Indicador de Forma de Provimento, Indicador de Conselho de Escola e Indicador de Construção da Proposta Pedagógica. Além disso, este trabalho indica que a variação não se apresenta somente entre as redes municipais agregadas por estado, mas entre os próprios municípios localizados em um mesmo território estadual, com variação intraestadual na efetividade da gestão democrática e de salários de diretores/as.

\section{REFERÊNCIAS}

ALVES, A. V. V. Atuação de Conselhos Escolares em redes municipais destaques no Ideb. In: XXV Simpósio Brasileiro II Congresso Ibero-americano de Política e Administração da Educação Jubileu de ouro da ANPAE (1961-2011), São Paulo, Cadernos ANPAE, 2011.

BEZERRA, A. A. Modalidade de provimento do dirigente escolar: mais um desafio para as políticas da educação municipal. Revista Brasileira de Estudos Pedagógicos. Brasília, v. 90, n. 224, p. 59-70, jan./abr. 2009.

BRASIL. Constituição. Constituição (1988). República Federativa do Brasil. Brasília, DF: Senado Federal, 1988

RPGE- Revista on line de Política e Gestão Educacional, Araraquara, v. 22, n. 3, p. 939-960, set./dez. 2018. $\quad$ E-ISSN:1519-9029. 
BRASIL. Lei n ${ }^{\circ} 9.394$ de 20 de dezembro de 1996. Estabelece a Lei de Diretrizes e bases da Educação Nacional. 1996. Diário Oficial [da] República Federativa do Brasil, Brasília, DF, 23 dez. 1996. Disponível em: http://www.planalto.gov.br/ccivil_03/leis/19394.htm. Acesso em: 15 out. 2015.

BRASIL. SR/PR. Democracia participativa: nova relação do Estado com a Sociedade. 2003-2010. 2. ed. Brasília, 2011.

DOURADO, L. F. A escolha de dirigentes escolares: políticas e gestão da educação no Brasil. In: FERREIRA, N. (org). Gestão democrática da educação: atuais tendências, novos desafios. 2. ed. São Paulo: Cortez, 2000.

DOURADO, L. F.; NAVARRO, I. P.; WITTMAN, L. C.; AGUIAR, M. A. S.; GRACINDO, R. V. Conselho escolar e financiamento da educação no Brasil. MEC/SEB. Brasília, 2006.

DOURADO, L. F.; OLIVEIRA, J. F. A qualidade da educação: perspectivas e desafios. Cadernos Cedes, Campinas, v. 29, n. 78, p. 201 - 215, maio/ago. 2009.

DOURADO, L. F.; OLIVEIRA, J.F.; SANTOS, C.A. A qualidade da educação: conceitos e definições. Série documental: textos para discussão. Instituto Nacional de Estudos e Pesquisas Educacionais Anísio Teixeira, n. 24, Brasília, 2007.

GADOTTI, M. Gestão democrática com participação popular no planejamento e na organização da educação nacional. Brasília: Ministério da Educação, 2014.

GOUVEIA, A. B.; SOUZA, A. R.; SCHNEIDER, G. Índice de Condições de Qualidade educacional: metodologia e indícios. Estudos em Avaliação Educacional. São Paulo, v. 22, n.48, jan./abr. 2011.

\section{INSTITUTO NACIONAL DE ESTUDOS E PESQUISAS EDUCACIONAIS ANÍSIO}

TEIXEIRA. Brasília: Ministério da Educação, 1937. Disponível em: http://www.inep.gov.br/. Acesso em: 17 fev. 2017.

SILVA, M. Q. Condições de qualidade das redes municipais de Ensino Fundamental no Brasil. 227 f. Dissertação (Mestrado em Educação) Programa de Pós-Graduação em Educação. Área de Concentração: Políticas Educacionais. Setor de Educação. Universidade Federal do Paraná. Curitiba, 2017.

SILVA, V. G. da. Projeto pedagógico e qualidade do ensino público: algumas categorias de análise. Cadernos de pesquisa, v.42, n. 145, p. 204-225 jan./abr. 2012.

SOUZA, A. R. Perfil da Gestão da Escola no Brasil. São Paulo: PUC, 2007. 302 f. Tese (Doutorado em educação) - Programa de Pós-Graduação em Educação: História, Política e Sociedade. Pontifícia Universidade Católica, São Paulo, 2007.

SOUZA, A. R. Explorando e construindo um conceito de gestão democrática. Educação em Revista. Belo Horizonte, v. 25, n. 03, p. 123-140, dez. 2009. 
SOUZA, A. R.; GOUVEIA, A. B.; SILVA, M. R.; SCHWENDLER, S. F. Gestão democrática da escola pública. IN: SOUZA, A. R. (org.) Coleção Gestão e Avaliação da Escola Pública. 68p. Universidade Federal do Paraná, Pró-Reitoria de Graduação e Ensino Profissionalizante, Centro Interdisciplinar de Formação Continuada de Professores;

Ministério da Educação, Secretaria de Educação Básica. Curitiba: Ed. Da UFPR, 2005.

\section{Como referenciar este artigo}

SOUZA, A. R.; SILVA, M. Q. Panorama Nacional das Condições de Gestão no Ensino Fundamental. Revista on line de Política e Gestão Educacional, Araraquara, v. 22, n. 3, p. 939-960, set./dez. 2018. E-ISSN:1519-9029. DOI: 10.22633/rpge.v22i3.11728

Submetido em: $14 / 08 / 2018$

Aprovado em: 30/08/2018 